histológico inicial. Discussão e conclusões: O GCG é uma lesão benigna, por vezes agressiva com rápida evolução e associada a dor e destruição das corticais ósseas. Pode estar relacionada com traumatismo da área, no entanto, no presente caso não se verificou. A histologia da lesão é característica: células gigantes multinucleadas em estroma mononuclear de células ovoides a fusiformes, com predominante extravasamento de eritrócitos e deposição de hemossiderina. No diagnóstico diferencial temos de ter em conta: quistos ou tumores odontogénicos e não odontogénicos, entre os quais, ameloblastoma e o tumor de células castanhas. Após um ano de follow-up, a doente está assintomática e radiologicamente não apresenta sinais de recidiva, com aparente regeneração óssea.

http://doi.org/10.24873/j.rpemd.2020.12.734

\section{\#011 Manifestação de um Linfoma na cavidade oral: relato de um caso clínico}

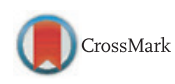

Maria J Morais*, Olga Vascan, Ana M. Marques, Beatriz Dominguez, Maria D. Lopes, José P. Figueiredo

Centro Hospitalar e Universitário de Coimbra

Introdução: O Linfoma é uma neoplasia que se caracteriza pela proliferação exacerbada de células linfoides ou dos seus precursores. Dividido em dois grupos - Linfomas Hodgkin e Não Hodgkin, podem apresentar uma manifestação nodular e extranodular. Em $40 \%$ dos casos, o linfoma Não Hodgkin é detetado em áreas extranodulares, com atingimento da região da cabeça e do pescoço em cerca de 11-33\%. Nesta localização, a maioria dos linfomas Não Hodgkin pertence à linhagem de células $\mathrm{B}$, com destaque para o Linfoma Difuso de Grandes Células B (80-85\% dos casos). O Linfoma Hodgkin tem uma manifestação extranodular em torno dos $4 \%$, sendo a região da cabeça e pescoço a mais acometida. $\mathrm{Na}$ cavidade oral, os linfomas representam a 3 . $^{\mathrm{a}}$ neoplasia mais comum, comportando-se frequentemente como uma doença extranodular, o que pode indicar a disseminação da doença. No entanto, o Linfoma Não Hodgkin pode ter origem nos tecidos orais sem que ocorra metastização para outros locais. O linfoma oral aparece como uma lesão volumosa dos tecidos moles, indolor e de limites difusos, localizada habitualmente no vestíbulo oral, na região posterior do palato duro ou na gengiva, que pode estar ulcerada. Na sua localização intra-óssea pode surgir dor, recorrentemente confundida com odontalgia e parestesias. Descrição do caso clínico: Homem, 74 anos, recorreu ao Serviço de Urgência de Estomatologia por tumefação no rebordo posterior do $1 .^{\circ} \mathrm{Q}$ com 1 ano de evolução. Em estudo pela Hematologia por suspeita de Linfoma, após perda ponderal de $10 \mathrm{~kg}$ nos últimos 3 meses. Negava outras queixas, nomeadamente outros sintomas B. Ao exame cervico-facial, observada uma tumefação cervical à esquerda, de $10 \mathrm{~cm}$ de maior eixo, com consistência pétrea e dolorosa à palpação. À observação intra-oral, apresentava uma lesão exofítica localizada no rebordo alveolar posterior do $1 .^{\circ} \mathrm{Q}$, com centro ulcerado e friável, em íntima relação com um implante dentário. Realizada biópsia incisional que revelou Linfoma Difuso de Grandes Células B.
Discussão e conclusões: O linfoma oral é difícil de reconhecer pela sua capacidade de mimetizar outras patologias, levando a um atraso do diagnóstico e consequentemente da terapêutica, verificando-se um agravamento do prognóstico. A biópsia incisional e estudo anatomo-patológico são o gold standard no diagnóstico e exclusão de outras patologias. A suspeita de malignidade explorada na história clínica detalhada e o trabalho multidisciplinar foram cruciais para o diagnóstico.

http://doi.org/10.24873/j.rpemd.2020.12.735

\#012 Abcesso Odontogénico Complicado: um caso clínico

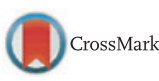

João Melo Oliveira*, Diana Breda, Sofia Correia, Olga Vascan, Margarida Mesquita, Francisco Marques

Centro Hospitalar e Universitário de Coimbra - Serviço de Estomatologia; Centro Hospitalar e Universitário de Coimbra - Serviço de Cirurgia Maxilo-Facial

Introdução: A incidência e a morbimortalidade das infeções de origem odontogénica diminuiu ao longo dos anos. Apesar de tudo, a maioria das infeções da cabeça e pescoço são de origem odontogénica e, se não tratadas devidamente, podem progredir para complicações potencialmente fatais. Este trabalho tem como objetivos a apresentação de um caso clínico de abcesso submandibular direito de origem odontogénica com necrose cutânea local e reforçar a importância de um diagnóstico e tratamento precoces. Descrição do caso clínico: Um homem saudável de 25 anos foi observado, no Serviço de Urgência do Centro Hospitalar e Universitário de Coimbra, por tumefação submandibular direita com uma semana de evolução e agravamento súbito nos últimos dois dias, apesar da antibioticoterapia oral prescrita pelo médico assistente. Ao exame objetivo apresentava trismus, ligeira parésia do ramo marginal direito do nervo facial e celulite até à região supra-clavicular ipsilateral com área de necrose cutânea e drenagem espontânea de conteúdo purulento. Foi realizado alargamento da loca do abcesso, com lavagem e desinfeção. Realizou ortopantomografia que revelou dente 4.8 semi-incluso mesio-angulado impactado no 4.7 cariado e com reação peri-apical. Optou-se por internar o doente no serviço de Cirurgia Maxilo-Facial para realização de antibioticoterapia empírica e corticoterapia intravenosa, mecanoterapia e cuidados de penso com Aquacel e Hidrogel. Ao 9. ${ }^{\circ}$ dia de internamento foi realizada, sob anestesia geral, extração simples de 4.7 e 4.8 e desbridamento da ferida cervical com avivamento dos bordos de pele, descolamento e encerramento cutâneo. Teve alta ao $12 .^{\circ}$ dia de internamento, melhorado e com boa evolução cicatricial. Discussão e conclusões: As infeções odontogénicas, geralmente, são infeções localizadas secundárias a cáries, doenças periodontais e pulpites. Se não tratadas devidamente, e sobretudo na presença de fatores que comprometam o sistema imunitário, podem progredir para formas mais complicadas que, embora raras, podem ser potencialmente fatais. Para evitar casos mais graves, é fundamental não só uma avaliação 
clínica completa mas também um tratamento precoce e adequado que previna essa disseminação e promova a sua resolução.

http://doi.org/10.24873/j.rpemd.2020.12.736

\#013 Maturação de lesões de displasia óssea periapical - seguimento de 3 anos

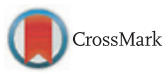

Rita Martins*, Mariana Maia, Pedro Cabeça Santos, Carolina Carreiro, Cristina Moreira, Catarina Fraga

Centro Hospitalar Universitário São João - Serviço de Estomatologia; Centro Hospitalar de Vila Nova de Gaia/ Espinho - Serviço de Estomatologia

Introdução: Numa displasia óssea ocorre a substituição de osso normal por tecido conjuntivo fibroso. Apresenta-se um caso de uma displasia óssea periapical em vigilância há 3 anos onde se pode observar o processo de maturação das lesões. Descrição do caso clínico: Mulher de 42 anos, raça caucasiana, sem antecedentes patológicos de relevo, encaminhada para a consulta de Estomatologia em fevereiro de 2018 pela identificação, em ortopantomografia de rotina, de lesões ósseas nas regiões apicais de 3.3 a 4.3. A doente estava assintomática, sem alterações de relevo no exame objetivo extraoral ou intraoral. Os dentes 3.3 a 4.3 apresentavam-se vitais e não apresentavam quaisquer alterações ao exame objetivo, nomeadamente mobilidade, dor à percussão, tumefação ou drenagem purulenta. Na ortopantomografia identificaram-se duas lesões bem delimitadas, de radiolucência mista, relacionadas com os ápices de 3.3 a 3.1 e 4.2 a 4.3. Na tomografia computorizada descrevia-se a coexistência de áreas radiolúcidas e radiopacas nos locais referidos, com discreto abaulamento cortical. Perante a hipótese diagnóstica de displasia óssea periapical optou-se por manter vigilância periódica. Até à presente data a situação clínica mantem-se sobreponível. Radiologicamente, tem-se verificado uma maturação progressiva das lesões, que atualmente se apresentam radiopacas com um fino bordo radiolúcido. Discussão e conclusões: A displasia óssea periapical é mais prevalente em mulheres de raça negra na $4 .^{a}-5 .^{a}$ décadas de vida. Geralmente assintomática, apresenta-se habitualmente como lesões multifocais, na região apical de dois ou mais dentes vitais, mandibulares anteriores. No estádio mais precoce, ocorre substituição do osso por tecido fibroso, traduzindo-se numa lesão radiolúcida com bordo esclerótico bem definido. No estádio misto a lesão apresenta focos radiopacos e radiolúcidos, sendo a maioria dos casos identificados nesta fase. No estádio final de calcificação, apresenta-se como uma massa radiopaca com uma margem radiolúcida. Durante a maturação, as lesões podem coalescer. O diagnóstico baseia-se na avaliação clínica e radiológica. Na ausência de sinais atípicos não se justifica a realização de biopsia. É aconselhável uma vigilância periódica bianual, para identificar qualquer alteração atípica, embora geralmente não seja necessário qualquer tratamento. Uma vez atingindo o estádio final da maturação as lesões permanecem estáveis.

http://doi.org/10.24873/j.rpemd.2020.12.737
\#014 Autofluorescência induzida pelo Laser comc método adjuvante no diagnóstico de Cancro Oral

Ana Catarina Vasconcelos*, Rosana Costa, Barbas do Amaral, Filomena Salazar, José Júlio Pacheco, Luís Monteiro

Instituto Universitário Ciências da Saúde do Norte - CESPU

Introdução: A fluorescência induzida por laser (LIF) é uma técnica espectroscópica que envolve a excitação de um alvo molecular por um feixe de radiação laser seguido pela deteção da emissão subsequente da radiação do alvo. A irradiação com laser de 405-nm origina uma autofluorescência própria da mucosa oral, onde alterações como lesões potencialmente malignas (LPM) ou cancro oral (CO) mostram alterações com perda de fluorescência. Assim o objetivo deste trabalho é mostrar a utilidade desta tecnologia com apresentação de um caso clínico no diagnostico de CO. Descrição do caso clínico: O caso clínico pertence a um indivíduo do sexo masculino, de 46 anos que se apresentou na consulta de medicina oral devido à presença de uma 'ferida na língua associada a um dente' com 1 mês de evolução. O utente não apresentava problemas de suade relevantes, ex-fumador com relato de hábitos alcoólicos exagerados. No exame clínico foi verificada uma lesão ulcerada no bordo esquerdo língua com cerca de $2 \mathrm{~cm}$ de maior diâmetro, assintomática. A lesão tinha bordos irregulares e a cor variava entre o vermelho e o amarelo. Aplicando a irradiação de laser 405nm, 05W foi identificada perda de fluorescência nomeadamente no bordo anterior da lesão que nos indicou o local mais indicado para realizar biópsia por punch de $4 \mathrm{~mm}$. O resultado mostrou carcinoma espinocelular e o utente foi enviado para consulta de grupo de Oncologia. Discussão e conclusões: O CO caracteriza-se pela sua alta capacidade invasiva, metastização ganglionar e sobrevivência reduzida. A seleção da área para biopsar ou identificação das margens é muitas vezes complicada em lesões potencialmente malignas e cancro oral. A utilização deste laser como método adjuvante na identificação do melhor local para biópsia, de forma a proporcionar um método minimamente invasivo, mostra-se de elevada importância nestes doentes, sendo um procedimento adjuvante seguro e eficaz.

http://doi.org/10.24873/j.rpemd.2020.12.738

\#015 Síndrome de Melkersson-Rosenthal: a propósito de um caso clínico

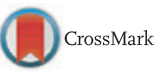

Sofia Correia*, Maria Inês Borges, João Melo Oliveira, Arturo López, Francisco Marques, José Pedro Figueiredo

Serviço de Estomatologia - Centro Hospitalar e Universitário de Coimbra; Serviço de Cirurgia Maxilo-Facial - Centro Hospitalar e Universitário de Coimbra

Introdução: A Síndrome de Melkersson-Rosenthal é uma doença rara, que se caracteriza pela tríade: paralisia facial periférica, macroquelite granulomatosa e língua fissurada. Na maioria dos casos a tríade clássica não é observada, sendo mais frequentes as formas mono ou oligossin- 